\title{
Oxygen Transfer Effects in a Two-Phase System of an Aqueous Phase and Liquid Perfluorochemical Subjected to Continuous Wave-Assisted Agitation in Disposable Bioreactor
}

\author{
Kamil Wierzchowski (D), Paweł Sobieszuk (D) and Maciej Pilarek*(D)
}

Faculty of Chemical and Process Engineering, Warsaw University of Technology, Waryńskiego 1, 00-645 Warsaw, Poland; kamil.wierzchowski.dokt@pw.edu.pl (K.W.); pawel.sobieszuk@pw.edu.pl (P.S.)

* Correspondence: maciej.pilarek@pw.edu.pl; Tel.: +48-22-234-62-72

check for updates

Citation: Wierzchowski, K.; Sobieszuk, P.; Pilarek, M. Oxygen Transfer Effects in a Two-Phase System of an Aqueous Phase and Liquid Perfluorochemical Subjected to Continuous Wave-Assisted Agitation in Disposable Bioreactor. Energies 2021, 14, 4381.

https://doi.org/10.3390/en14144381

Academic Editor: Marek Ochowiak

Received: 7 May 2021

Accepted: 17 July 2021

Published: 20 July 2021

Publisher's Note: MDPI stays neutral with regard to jurisdictional claims in published maps and institutional affiliations.

Copyright: (c) 2021 by the authors. Licensee MDPI, Basel, Switzerland. This article is an open access article distributed under the terms and conditions of the Creative Commons Attribution (CC BY) license (https:// creativecommons.org/licenses/by/ $4.0 /)$.

\begin{abstract}
Systems of two immiscible liquid phases-aqueous phase (i.e., distilled water $\left(\mathrm{dH}_{2} \mathrm{O}\right)$ or phosphate-buffered saline (PBS)) and liquid perfluorochemical (i.e., perfluorodecalin (PFD))—were subjected to wave-assisted agitation, i.e., oscillatory rocked, in a disposable bag-like container in a ReadyToProcess $\mathrm{WAVE}^{\mathrm{TM}} 25$ bioreactor, to recognize oxygen transfer effects and effectivity of the surface aeration. According to the DoE methodology, values of the volumetric liquid-side mass transfer $\left(k_{\mathrm{L}} a\right)$ coefficient for $\mathrm{dH}_{2} \mathrm{O}$, PBS, $\mathrm{dH}_{2} \mathrm{O}-\mathrm{PFD}$, and PBS-PFD systems were determined for the whole range of operating parameters of the WAVE 25 bioreactor. A significantly higher maximal value of $k_{\mathrm{L}} a$ was found for waving $\mathrm{dH}_{2} \mathrm{O}$ than for $\mathrm{dH}_{2} \mathrm{O}$-PFD (i.e., $0.00460 \mathrm{~s}^{-1}$ vs. $0.00331 \mathrm{~s}^{-1}$, respectively) compared to more equal maximal values of $k_{\mathrm{L}} a$ reached for PBS and PBS-PFD $\left(0.00355 \mathrm{~s}^{-1}\right.$ vs. $0.00341 \mathrm{~s}^{-1}$, respectively). The interface development factor $(f)$ depended on the interfacial area $a$, and the enhancement factor $\left(E^{\mathrm{PFD}}\right)$, depending on $k_{\mathrm{L}} a$, was introduced to quantitatively identify the mass transfer effects in the systems of waving two immiscible liquids. The phase of PFD was identified as the reservoir of oxygen. Dimensional correlations were proposed for the prediction of the $k_{\mathrm{L}} a$ coefficient, in addition to the $f$ and $E^{\mathrm{PFD}}$ factors. The presented correlations, and the set of $k_{L} a$ values, can be directly applied to predict oxygen transfer effects reached under continuous oscillatory rocked systems containing aqueous phase and liquid perfluorochemical.
\end{abstract}

Keywords: liquid perfluorochemical (perfluorocarbon); mass transfer; wave-assisted agitation; disposable bag-like container; cell culture; dimensional exponential correlation methodology

\section{Introduction}

Synthetic liquid perfluorochemicals (PFCs; synonym: perfluorocarbons), which dissolve gases according to Henry's Law, have been adopted in medicinal liquid ventilation procedures [1,2] and bioprocess engineering. PFCs have been repeatedly applied as biochemically inert liquid carriers of respiratory gases in many cell culture systems during the past three decades [3-5]. The gas transfer rate into PFCs increases linearly with the partial pressure of a component in the gaseous phase [6,7] in opposition to the sigmoid dissociation curve that is characteristic of biological oxygen carriers. The lack of chemical bonds between molecules of oxygen and PFC allows the efficient release of gas from layered or dispersed PFCs into the aqueous phase. Due to the physicochemical properties exhibited by liquid PFCs (i.e., immiscibility with aqueous media), some investigators recommend using them as efficient liquid gas carriers in bioprocesses with biomass of animal or plant cells/tissues performed in various bioreactor systems, as an additional liquid layer at the bottom of a bioreactor vessel [8-10], or as dispersed droplets of utilized PFC [11-13] in intensively agitated systems.

Currently, in addition to conventional stirred tank stainless steel bioreactors, disposable (i.e., single-use) bioreactors are recognized as suitable equipment for developing and scaling-up in vitro bioprocesses with animal cells maintained in both forms: suspended 
biomass and as biomass integrated with biomaterial-based constructs or microcarriers. The main systematic difference distinguishing disposable bioreactors from typical bioreactors is the pre-sterilized single-use container made of polymer-based multi-layer plastic, which is applied as a flexible-in-shape bag (i.e., pillow-like shape) for preparation of individual culture environment [14,15]. Shape and size (i.e., dimensions and volume) of the culture bag determine the possible mechanism of agitation, which may be applied for efficient mixing of liquid phase poured into such a pillow-shaped container.

Two independent systems of disposable bioreactors are recommended for performing and scaling-up cultures of fragile mammalian cells. The first is a group of single-use stirred tank bioreactors presenting similarity to conventional stirred tanks made of stainless steel typically applied in chemical engineering $[16,17]$. The second group is representing by mechanically driven oscillating systems characterized by mixing driven by sequential horizontal raising and lowering of the culture bag fixed on the oscillating platform of the bioreactor [18-21]. Depending on the intensity of the operational parameters (i.e., rocking angle and rate, filling volume, and fluid properties), the liquid phase closed inside the culture bag ripples, waves, or popples, which finally provides wave-induced mixing of the culture medium and its surface aeration $[22,23]$.

The new and original bioprocessing concept enhances mass transfer effects inside the disposable culture bag by supplementing the waving culture system with a continuous layer of PFC-based oxygen carrier poured at the bottom of the disposable container. Accordingly, the primary aim of the study was to quantitatively recognize the oxygen transfer effects that occur under conditions of wave-assisted agitation in the system of aqueous phase supported with the perfluorinated gas carrier, which both were waved in a 2.0 liter disposable culture bag of a ReadyToProcess WAVE ${ }^{\mathrm{TM}} 25$ bioreactor (WAVE 25; Citiva, formerly GE Healthcare, US).

Pre-sterilized distilled water $\left(\mathrm{dH}_{2} \mathrm{O}\right)$ and phosphate-buffered saline (PBS) were used as two independent aqueous phases, and pre-sterilized perfluorodecalin (PFD) was examined as a liquid PFC-based oxygen carrier. The detailed influences of operational parameters, such as angle $(\alpha)$ and frequency $(\omega)$ of oscillations, in addition to volumetric gas flow through a culture vessel $\left(Q_{G}\right)$, on oxygen mass transfer effects, were identified according to a methodology based on Design of Experiments (DoE). Furthermore, values of the volumetric liquid-side mass transfer coefficient $\left(k_{\mathrm{L}} a\right)$ obtained independently in $\mathrm{dH}_{2} \mathrm{O}$ PFD and PBS-PFD systems were also determined and mutually compared. Finally, the correlations predicting the relation of values of the $k_{\mathrm{L}} a$ coefficient and presets of operation parameters in WAVE 25 for both of the studied aqueous phase-PFD systems were initially introduced.

\section{Materials and Methods}

\subsection{Setup of Disposable Bioreactor Supporting Continuous Wave-Assisted Agitation}

A ReadyToProcess WAVE ${ }^{\mathrm{TM}} 25$ bioreactor system (WAVE 25, Citiva, formerly GE Healthcare, US) equipped with a $2.0 \mathrm{~L}$ disposable culture bag (Cellbag; Citiva, US) was used in the experiments. For online measurements of the value of dissolved oxygen (DO) in the aqueous phase, the miniaturized optical (i.e., spectrophotometric) single-use DO sensor integrated within the WAVE 25 system was used. The value of DO was measured with a sampling frequency of $1 \mathrm{~Hz}$. The signals from the DO sensor were transferred by optical fiber to the central bioreactor control unit (CBCU, Citiva, US), which automatically integrated the signals and collected data from the DO sensor. All experiments were performed at $37^{\circ} \mathrm{C}$.

\subsection{Operating Parameters of WAVE 25 System}

Based on one of our previously published reports [22], the following operating parameters of WAVE 25 were taken into consideration as factors that significantly influence oxygen transfer effects in the studied system: 
- $\quad \alpha$ and $\omega$, which commonly characterize the vertical movements of the Cellbag fixed to the rocking tray of WAVE 25, i.e., the parameters directly associated with waves mechanically generated on liquids inside the Cellbag;

- $Q_{G}$, which characterizes the gaseous phase flowing over the liquid phases in the Cellbag during continuous wave-assisted agitation.

\subsection{Composition of Liquid Phases and Gas Mixture}

$\mathrm{dH}_{2} \mathrm{O}$ or PBS were independently used as aqueous phases. PFD, as an equimolar mixture of cis/trans isomers of PFD with $\geq 99 \%$ purity (abcr $\mathrm{GmbH}, \mathrm{DE}$ ), was applied as an additional liquid phase. Before each experiment, the Cellbag system containing two immiscible liquid phases, i.e., $\mathrm{dH}_{2} \mathrm{O}-\mathrm{PFD}$ and PBS-PFD, was aseptically deoxygenated in a continuously operating WAVE 25 by introducing pure $\mathrm{N}_{2}$ into the disposable container until total removal of $\mathrm{O}_{2}$ from both contacting liquid phases, which finally resulted in aqueous phase characterized by $\mathrm{DO}$ equal to the value of $0 \%$.

In all experiments, a gas mixture containing $21 \%$ pure $\mathrm{O}_{2}$ and $79 \%$ pure $\mathrm{N}_{2}$ was applied for the oxygenation of the studied systems. $\mathrm{CBCU}$ provided automatic mixing of the defined gas mixture with specified partial pressures of $\mathrm{O}_{2}\left(\mathrm{p}_{\mathrm{O} 2}\right)$ and $\mathrm{N}_{2}\left(\mathrm{p}_{\mathrm{N} 2}\right)$ before introducing it into the Cellbag.

\section{4. $D o E$}

All experiments were planned and evaluated with STATISTICA Data Miner 13.0 (StatSoft, PL). The Box-Behnken design (BBD) employing three levels of varied factors (i.e., operating parameters) was applied to minimize the number of experimental runs required. The set of the operating parameters recognized as independent factors and employed in the DoE-aided experiments is presented in Table 1. This represents the whole spectrum of operational parameter values that are accessible (and strictly defined) by the manufacturer of WAVE 25.

Table 1. Values of the operating parameters are recognized as independent factors employed in DoE-aided analysis based on BBD.

\begin{tabular}{|c|c|c|c|c|c|}
\hline \multirow[b]{2}{*}{ Factor } & \multirow{2}{*}{$\begin{array}{c}\text { Range of Parameter } \\
\text { Accessible in WAVE } 25\end{array}$} & \multicolumn{3}{|c|}{ Value of Parameter Employed in BBD } & \multirow[b]{2}{*}{ Unit } \\
\hline & & $\begin{array}{c}-1 \\
\text { (Minimal) }\end{array}$ & 0 (Centre) & $\begin{array}{c}+1 \\
\text { (Maximal) }\end{array}$ & \\
\hline$\alpha$ & $2-12$ & 2 & 7 & 12 & {$\left[{ }^{\circ}\right]$} \\
\hline$\omega$ & $0.033-0.667$ & 0.033 & 0.350 & 0.667 & {$\left[\mathrm{~s}^{-1}\right]$} \\
\hline$Q_{G}$ & $0.17 \times 10^{-5}-1.67 \times 10^{-5}$ & $0.17 \times 10^{-5}$ & $0.92 \times 10^{-5}$ & $1.67 \times 10^{-5}$ & {$\left[\mathrm{~m}^{3} \mathrm{~s}^{-1}\right]$} \\
\hline
\end{tabular}

\subsection{Determination of the $k_{L}$ a Coefficient}

The scheme of the experimental system is introduced in Figure 1. The disposable Cellbag contained liquid phases, i.e., $0.3 \mathrm{dm}^{3} \mathrm{dH}_{2} \mathrm{O}$ or PBS and $0.15 \mathrm{dm}^{3} \mathrm{PFD}$, and the gas mixture flowed over the aqueous phase with the volumetric flow $Q_{G}$. The Cellbag was subjected to oscillatory-driven wave-induced agitation at defined values of $\alpha$ and $\omega$. The oxygen transfer in the system between gas and liquid phases was a non-steady process of oxygen absorption from the gas mixture into the aqueous phase and from the aqueous phase into PFD. Due to the negligibility of the slight amount of oxygen absorbed in the aqueous phase, constant values of $Q_{\mathrm{G}}$ and $\mathrm{p}_{\mathrm{O} 2}$ (at both inlet and outlet of the bag-like container) may be assumed. Similarly, the constant value of liquid phase volumes may be assumed according to the negligibility of the vaporization of distilled water in the culture bag and the perfect mixing of the liquid phases. 


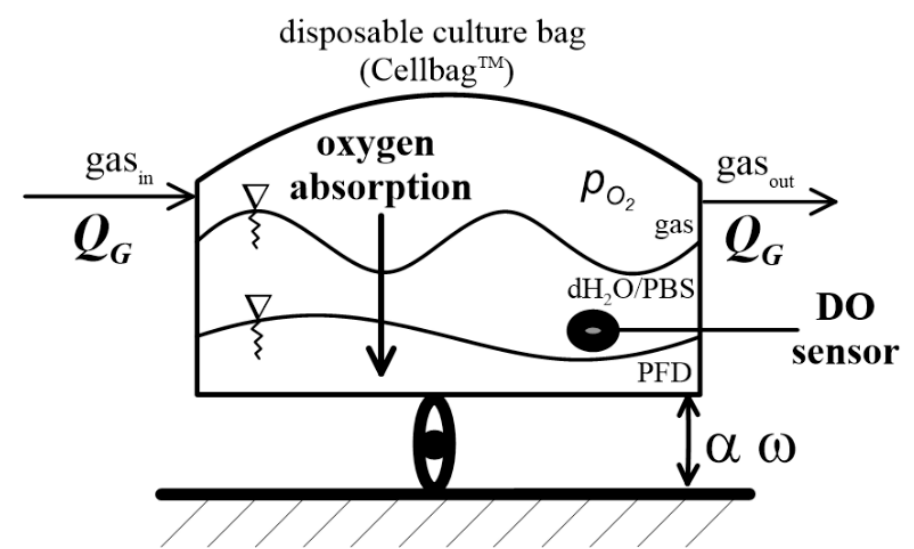

Figure 1. The scheme of non-steady-state oxygen absorption from the gas mixture into liquid phases of the studied system subjected to oscillatory-driven wave-induced agitation in the Cellbag container.

The $k_{\mathrm{L}} a$ coefficient was determined based on the oxygen balance in the aqueous phase:

$$
d c_{\mathrm{L}} \times d t^{-1}=k_{\mathrm{L}} a \times\left(c_{\mathrm{L}}^{*}-c_{\mathrm{L}}\right)
$$

The graphical interpretation of Equation (1), in the form of the directly proportional relationship between the derivative $d c_{\mathrm{L}} \times d t^{-1}$ and the driving force (i.e., the difference $c_{\mathrm{L}}^{*}-c_{\mathrm{L}}$ ), simplifies the determination of the $k_{\mathrm{L}} a$ coefficient, as presented in Figure 2.

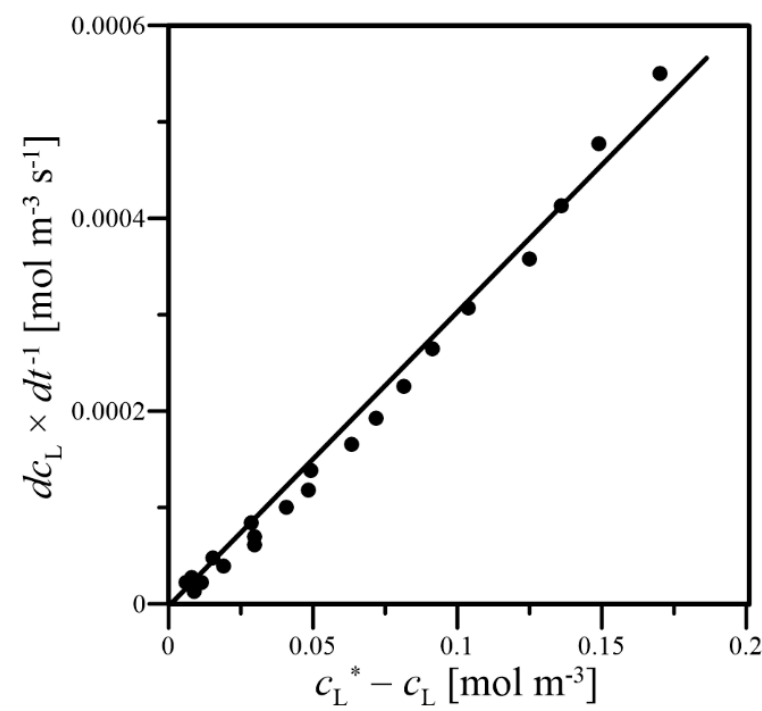

Figure 2. Graphical method for determination of the $k_{\mathrm{L}} a$ coefficient.

\section{Results}

Based on the DoE-aided analysis introduced in Table 1, three operational parameters, i.e., $\alpha, \omega$ and $Q_{G}$, were introduced in the $\mathrm{BBD}$, as previously recognized parameters influencing significantly on oxygen transfer the studied systems. In total, 104 runs of experiments (i.e., 23 typical runs with three extra center point runs for four different studied systems) are presented in Table 2, as the BBD devised to recognize the influence of operating parameters on the values of the $k_{\mathrm{L}} a$ coefficient obtained for the studied systems under wave-induced mixing. According to this, $k_{\mathrm{L}} a$ values were determined for the minimal, center, and maximal values (i.e., introduced in BBD as $-1,0$, and +1 , respectively) of $\alpha, \omega$, and $Q_{\mathrm{G}}$, for four independent systems: $\mathrm{dH}_{2} \mathrm{O}$ (i.e., $k_{\mathrm{L}} a_{\mathrm{dH}_{2} \mathrm{O}}$ ), PBS (i.e., $k_{\mathrm{L}} a_{\mathrm{PBS}}$ ),

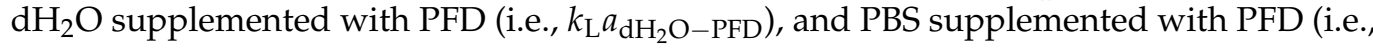
$\left.k_{\mathrm{L}} a_{\mathrm{PBS}-\mathrm{PFD}}\right)$. 
Table 2. Variable levels were introduced to the BBD with three operation parameters $\left(\alpha, \omega, Q_{G}\right)$ to determine the $k_{\mathrm{L}} a$ coefficient for four independently studied gas-liquid(s) systems.

\begin{tabular}{|c|c|c|c|c|c|c|c|}
\hline \multirow{3}{*}{ Run } & \multirow{2}{*}{\multicolumn{3}{|c|}{ Variable Levels }} & \multicolumn{4}{|c|}{$k_{\mathrm{L}} a$ Characterized Gas-Liquid(s) Systems } \\
\hline & & & & \multirow{2}{*}{$\begin{array}{l}k_{\mathrm{L}} a_{\mathrm{dH}_{2} \mathrm{O}} \\
{\left[\mathrm{s}^{-1}\right]}\end{array}$} & \multirow{2}{*}{$\begin{array}{l}k_{\mathrm{L}} a_{\mathrm{dH}_{2} \mathrm{O}-\mathrm{PFD}} \\
{\left[\mathrm{s}^{-1}\right]}\end{array}$} & \multirow{2}{*}{$\begin{array}{l}k_{\mathrm{L}} a_{\text {PBS }} \\
{\left[\mathrm{s}^{-1}\right]}\end{array}$} & \multirow{2}{*}{$\begin{array}{l}k_{\mathrm{L}} a_{\mathrm{PBS}-\mathrm{PFD}} \\
{\left[\mathrm{s}^{-1}\right]}\end{array}$} \\
\hline & $\alpha$ & $\omega$ & $Q_{\mathrm{G}}$ & & & & \\
\hline 1 & -1 & 0 & -1 & 0.00055 & 0.00027 & 0.00056 & 0.00023 \\
\hline 2 & -1 & 0 & 0 & 0.00255 & 0.00036 & 0.00186 & 0.00030 \\
\hline 3 & -1 & 0 & 1 & 0.00319 & 0.00030 & 0.00101 & 0.00029 \\
\hline 4 & -1 & 1 & -1 & 0.00058 & 0.00044 & 0.00057 & 0.00035 \\
\hline 5 & -1 & 1 & 0 & 0.00308 & 0.00073 & 0.00139 & 0.00079 \\
\hline 6 & -1 & 1 & 1 & 0.00458 & 0.00081 & 0.00156 & 0.00079 \\
\hline 7 & 0 & -1 & -1 & 0.00048 & 0.00017 & 0.00041 & 0.00010 \\
\hline 8 & 0 & -1 & 0 & 0.00131 & 0.00013 & 0.00057 & 0.00010 \\
\hline 9 & 0 & -1 & 1 & 0.00150 & 0.00013 & 0.00102 & 0.00016 \\
\hline 10 & 0 & 0 & -1 & 0.00061 & 0.00051 & 0.00055 & 0.00050 \\
\hline 11 & 0 & 0 & 0 & 0.00282 & 0.00107 & 0.00173 & 0.00108 \\
\hline 12 & 0 & 0 & 1 & 0.00460 & 0.00126 & 0.00311 & 0.00092 \\
\hline 13 & 0 & 1 & -1 & 0.00057 & 0.00054 & 0.00057 & 0.00053 \\
\hline 14 & 0 & 1 & 0 & 0.00285 & 0.00200 & 0.00178 & 0.00162 \\
\hline 15 & 0 & 1 & 1 & 0.00456 & 0.00331 & 0.00325 & 0.00254 \\
\hline 16 & 1 & -1 & -1 & 0.00032 & 0.00048 & 0.00028 & 0.00015 \\
\hline 17 & 1 & -1 & 0 & 0.00165 & 0.00017 & 0.00139 & 0.00018 \\
\hline 18 & 1 & -1 & 1 & 0.00184 & 0.00015 & 0.00176 & 0.00019 \\
\hline 19 & 1 & 0 & 0 & 0.00279 & 0.00145 & 0.00203 & 0.00141 \\
\hline 20 & 1 & 0 & 1 & 0.00432 & 0.00167 & 0.00160 & 0.00173 \\
\hline 21 & 1 & 1 & -1 & 0.00061 & 0.00057 & 0.00058 & 0.00051 \\
\hline 22 & 1 & 1 & 0 & 0.00292 & 0.00251 & 0.00260 & 0.00228 \\
\hline 23 & 1 & 1 & 1 & 0.00382 & 0.00295 & 0.00355 & 0.00341 \\
\hline 24 & 0 & 0 & 0 & 0.00300 & 0.00094 & 0.00191 & 0.00107 \\
\hline 25 & 0 & 0 & 0 & 0.00298 & 0.00138 & 0.00271 & 0.00101 \\
\hline 26 & 0 & 0 & 0 & 0.00363 & 0.00153 & 0.00270 & 0.00098 \\
\hline
\end{tabular}

As is commonly known, the $k_{\mathrm{L}} a$ coefficient consists of two factors: the liquid side mass transfer coefficient $\left(k_{\mathrm{L}}\right)$ and the interfacial area of mass transfer $(a)$. The $k_{\mathrm{L}}$ values can be approximated by the Higby penetration mass transfer model $[20,23]$, which the following equation can represent:

$$
k_{\mathrm{L}}=2 \times\left(D_{\mathrm{L}} \times \pi^{-1} \times \tau^{-1}\right)^{0.5}
$$

where: $D_{\mathrm{L}}$ is coefficient of oxygen diffusivity in liquid phase (i.e., $D_{\mathrm{L}}=3.06 \times 10^{-9} \mathrm{~m}^{2} \mathrm{~s}^{-1}$ ) and $\tau$ is contact time [s].

Based on the values of the $k_{\mathrm{L}} a$ coefficient determined for $\mathrm{dH}_{2} \mathrm{O}$ and PBS presented in Table 2, and values of $k_{\mathrm{L}}$ coefficient calculated from Equation (2), the value of $a$ can be simply estimated from the following equation:

$$
a=k_{\mathrm{L}} a \times k_{\mathrm{L}}^{-1}
$$

The values of $a$ estimated from Equation (3) represent the real interface for oxygen transfer from the gas phase into the liquid phase, which can be compared with the physical interfacial area $\left(a^{\prime}\right)$ estimated for non-mixed conditions. For example, based on the real geometry of the Cellbag, which contained $0.3 \mathrm{dm}^{3}$ of liquid phase (please see Figure 1), the value of $a^{\prime}$ can be calculated from the following equation:

$$
a^{\prime}=F \times V_{\mathrm{L}}^{-1}
$$

where: $F$ is the interfacial area between gas and liquid (i.e., $0.043 \mathrm{~m}^{2}$ ), and $V_{\mathrm{L}}$ is the volume of the liquid phase (i.e., $3 \times 10^{-4} \mathrm{~m}^{3}$ ). 
To analyze the influence of operating parameters that characterize oscillatory-driven wave-type agitation in WAVE 25, i.e., $\alpha$ and $\omega$, on the value of $a$, the interface development factor $(f)$ was proposed. The values of $f$ for both studied aqueous phases of $\mathrm{dH}_{2} \mathrm{O}$ and PBS were calculated from the following equation:

$$
\begin{aligned}
f_{\mathrm{dH}_{2} \mathrm{O}} & =a_{\mathrm{dH}_{2} \mathrm{O}} \times a^{\prime-1} \\
f_{\mathrm{PBS}} & =a_{\mathrm{PBS}} \times a^{\prime-1}
\end{aligned}
$$

Moreover, to quantitatively analyze the influence of PFD supplementation on the level of the $k_{\mathrm{L}} a$ coefficient obtained in the studied two-liquid systems (i.e., $\mathrm{dH}_{2} \mathrm{O}-\mathrm{PFD}$ and PBS-PFD), the enhancement factors $E_{\mathrm{dH} 2 \mathrm{O}}{ }^{\mathrm{PFD}}$ and $E_{\mathrm{PBS}}{ }^{\mathrm{PFD}}$ were introduced as follows:

$$
\begin{gathered}
E_{\mathrm{dH}_{2} \mathrm{O}}^{\mathrm{PFD}}=k_{\mathrm{L}} a_{\mathrm{dH_{2 } \mathrm { O }}-\mathrm{PFD}} \times k_{\mathrm{L}} a_{\mathrm{dH}_{2} \mathrm{O}}^{-1} \\
E_{\mathrm{PBS}}^{\mathrm{PFD}}=k_{\mathrm{L}} a_{\mathrm{PBS}-\mathrm{PFD}} \times k_{\mathrm{L}} a_{\mathrm{PBS}}^{-1}
\end{gathered}
$$

analogously to enhancement factors for $\mathrm{CO}_{2}$ absorption with chemical reaction and without chemical reaction previously defined by DeCoursey [24].

The values of four originally introduced factors $-f_{\mathrm{dH}_{2} \mathrm{O}}, f_{\mathrm{PBS}}, E_{\mathrm{dH}_{2} \mathrm{O}}^{\mathrm{PFD}}$ and $E_{\mathrm{PBS}}^{\mathrm{PFD}}-$

\begin{tabular}{|c|c|c|c|c|c|c|c|}
\hline \multirow{3}{*}{ Run } & \multirow{2}{*}{\multicolumn{3}{|c|}{ Variable Levels }} & \multicolumn{4}{|c|}{ Factors Characterized Gas-Liquid(s) Systems } \\
\hline & & & & \multirow{2}{*}{$\frac{f_{\mathrm{dH}_{2} \mathrm{O}}}{[-]}$} & \multirow{2}{*}{$\begin{array}{c}f_{\text {PBS }} \\
{[-]}\end{array}$} & \multirow{2}{*}{$\begin{array}{c}E_{\mathrm{dH}_{2} \mathrm{O}}^{\mathrm{PFD}} \\
{[-]}\end{array}$} & \multirow{2}{*}{$\begin{array}{c}E_{\text {PBS }}^{\text {PFD }} \\
{[-]}\end{array}$} \\
\hline & $\alpha$ & $\omega$ & $Q_{\mathrm{G}}$ & & & & \\
\hline 1 & -1 & 0 & -1 & 1.953 & 2.205 & 0.492 & 0.403 \\
\hline 2 & -1 & 0 & 0 & 3.876 & 3.129 & 0.140 & 0.163 \\
\hline 3 & -1 & 0 & 1 & 3.605 & 1.259 & 0.093 & 0.287 \\
\hline 4 & -1 & 1 & -1 & 2.072 & 2.237 & 0.756 & 0.623 \\
\hline 5 & -1 & 1 & 0 & 4.687 & 2.338 & 0.237 & 0.572 \\
\hline 6 & -1 & 1 & 1 & 5.165 & 1.953 & 0.177 & 0.508 \\
\hline 7 & 0 & -1 & -1 & 1.725 & 1.623 & 0.345 & 0.243 \\
\hline 8 & 0 & -1 & 0 & 1.986 & 0.963 & 0.100 & 0.180 \\
\hline 9 & 0 & -1 & 1 & 1.693 & 1.269 & 0.087 & 0.153 \\
\hline 10 & 0 & 0 & -1 & 2.181 & 2.172 & 0.841 & 0.914 \\
\hline 11 & 0 & 0 & 0 & 4.294 & 2.904 & 0.378 & 0.628 \\
\hline 12 & 0 & 0 & 1 & 5.194 & 3.878 & 0.274 & 0.295 \\
\hline 13 & 0 & 1 & -1 & 2.022 & 2.259 & 0.951 & 0.932 \\
\hline 14 & 0 & 1 & 0 & 4.332 & 3.002 & 0.701 & 0.910 \\
\hline 15 & 0 & 1 & 1 & 5.147 & 4.061 & 0.725 & 0.780 \\
\hline 16 & 1 & -1 & -1 & 1.140 & 1.097 & 1.496 & 0.550 \\
\hline 17 & 1 & -1 & 0 & 2.506 & 2.343 & 0.105 & 0.128 \\
\hline 18 & 1 & -1 & 1 & 2.078 & 2.192 & 0.083 & 0.108 \\
\hline 19 & 1 & 0 & 0 & 4.252 & 3.419 & 0.520 & 0.696 \\
\hline 20 & 1 & 0 & 1 & 4.874 & 2.001 & 0.386 & 1.080 \\
\hline 21 & 1 & 1 & -1 & 2.161 & 2.281 & 0.945 & 0.875 \\
\hline 22 & 1 & 1 & 0 & 4.438 & 4.373 & 0.861 & 0.879 \\
\hline 23 & 1 & 1 & 1 & 4.313 & 4.432 & 0.773 & 0.961 \\
\hline 24 & 0 & 0 & 0 & 4.569 & 3.208 & 0.314 & 0.560 \\
\hline 25 & 0 & 0 & 0 & 4.526 & 4.569 & 0.463 & 0.373 \\
\hline 26 & 0 & 0 & 0 & 5.520 & 4.550 & 0.421 & 0.362 \\
\hline
\end{tabular}
calculated for all runs of the evaluated BBD are shown in Table 3.

Table 3. The values of the interface development factors $-f_{\mathrm{dH}_{2} \mathrm{O}}, f_{\mathrm{PBS}}$ - and the enhancement factors $-E_{\mathrm{dH}_{2} \mathrm{O}^{\prime}}^{\mathrm{PFD}} E_{\mathrm{PBS}}^{\mathrm{PFD}}-$ calculated for all runs of the evaluated BBD.

The values of $E_{\mathrm{dH}_{2} \mathrm{O}}^{\mathrm{PFD}}$ and $E_{\mathrm{PBS}}^{\mathrm{PFD}}$ estimated for the present systems reached values smaller than 1.0. It appears that supplementation of the aqueous phase with PFD resulted in lower values of the $k_{\mathrm{L}} a$ coefficient than $k_{\mathrm{L}} a$ noted for pure aqueous phases. A similar relationship 
was observed previously by Ju [25] for the emulsion system of water and perfluorocarbon. $\mathrm{Ju}$ [25] reported smaller values of $k_{\mathrm{L}} a$ coefficient for water-perfluorocarbon emulsions than for the perfluorocarbon-free system.

The relationships between values of the $f$ factor calculated for $\mathrm{dH}_{2} \mathrm{O}$ and PBS, and various values of $\alpha$ and $\omega$, are graphically presented in Figure 3. It was found that the obtained values of both $f_{\mathrm{dH}_{2} \mathrm{O}}$ and $f_{\mathrm{PBS}}$ monotonically increased for higher values of $\alpha$ and $\omega$. Additionally, the observed relationships between the experimentally determined values of $f_{\mathrm{dH}_{2} \mathrm{O}}$ against $\alpha$ and $\omega$ (Figure 3A,B) revealed very similar effects to predicted values of $f_{\text {PBS }}$ (Figure $3 \mathrm{C}, \mathrm{D}$ ).
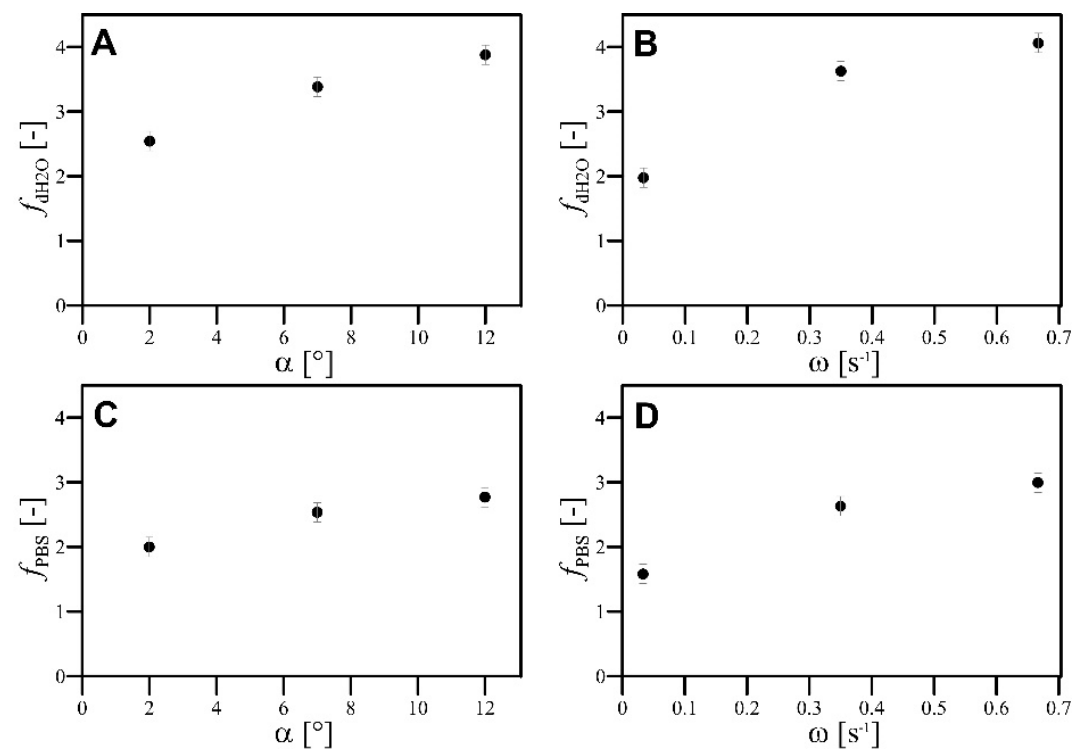

Figure 3. Graphical relationships between values of the $f$ factor characterizing both studied aqueous phases calculated for various values of $\alpha$ and $\omega$ evaluated in the BBD: $f_{\mathrm{dH}_{2} \mathrm{O}}(\mathbf{A}, \mathbf{B})$ and $f_{\mathrm{PBS}}(\mathbf{C}, \mathbf{D})$.

The relationships between values of the $E^{\mathrm{PFD}}$ factor calculated for $\mathrm{dH}_{2} \mathrm{O}$ and $\mathrm{PBS}$, and various values of $\alpha, \omega$, and $Q_{\mathrm{G}}$ are graphically presented in Figure 4 . In the case of the influence of $\alpha$ and $\omega$, the values of $E_{\mathrm{dH}_{2} \mathrm{O}}^{\mathrm{PFP}}$ and $E_{\mathrm{PBS}}^{\mathrm{PFD}}$ increased monotonically according to the increase in these operating parameters. Otherwise, it was observed that the increase in the value of $Q_{\mathrm{G}}$ resulted in a monotonical decrease in the noted values of both $E_{\mathrm{dH}_{2} \mathrm{O}}^{\mathrm{PFD}}$ and $E_{\mathrm{PBS}}^{\mathrm{PFD}}$. Furthermore, the presented relationships between the values of $E_{\mathrm{dH}_{2} \mathrm{O}}^{\mathrm{PFD}}$ calculated for various values of $\alpha, \omega$, and $Q_{G}$, shown in Figure $4 \mathrm{~A}-\mathrm{C}$, revealed very similar effects, resulting from the values of $E_{\mathrm{PBS}}^{\mathrm{PFD}}$, which are presented in Figure $4 \mathrm{D}-\mathrm{F}$. 

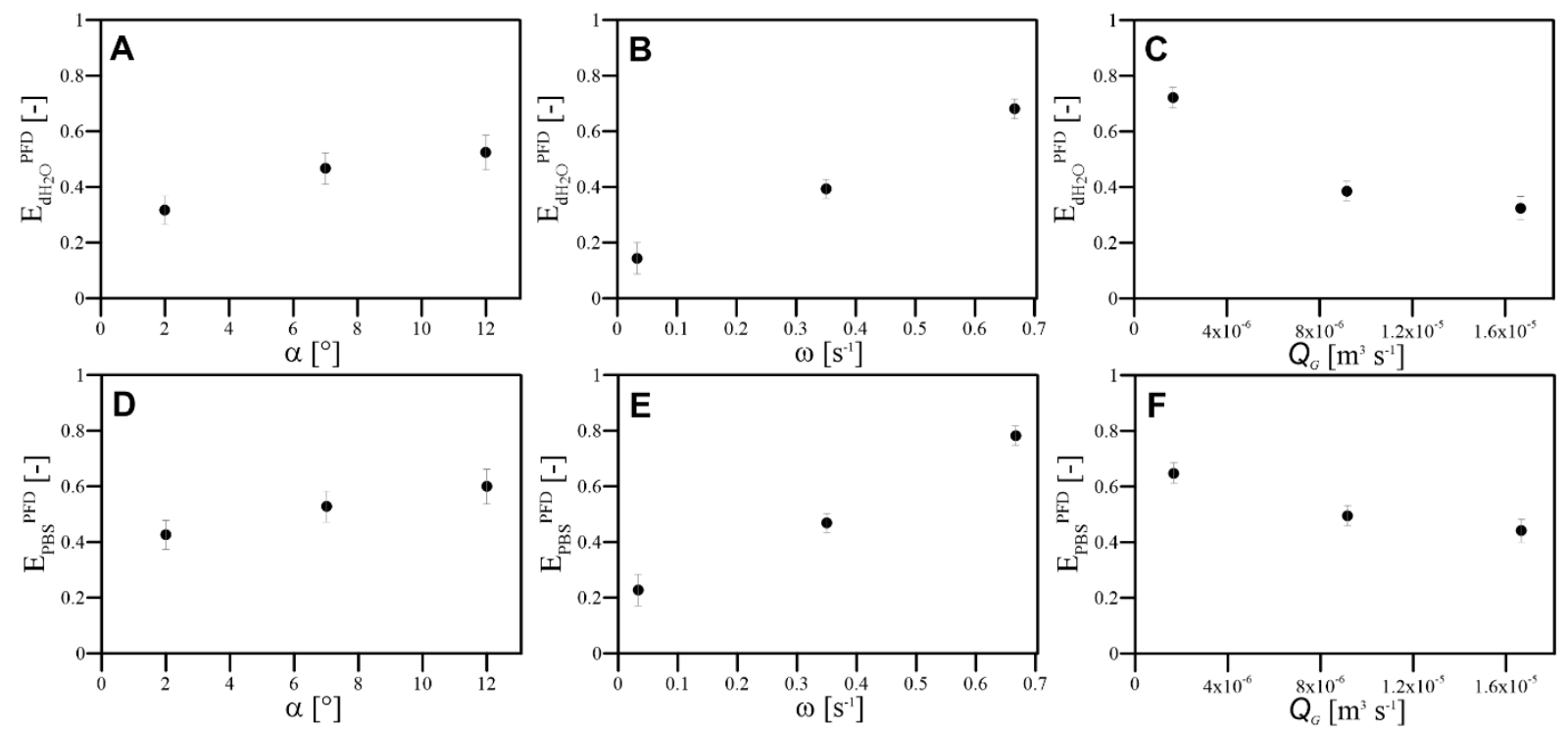

Figure 4. Graphical relationships between values of the $E^{\mathrm{PFD}}$ factor characterizing both studied aqueous phases calculated for various values of $\alpha, \omega$, and $Q_{\mathrm{G}}$ evaluated in the BBD: $E_{\mathrm{dH}_{2} \mathrm{O}}^{\mathrm{PFD}}(\mathbf{A}-\mathrm{C})$ and $E_{\mathrm{PBS}}^{\mathrm{PFD}}(\mathbf{D}-\mathbf{F})$.

\section{Discussion}

To date, liquid PFC-based oxygen carriers have been repeatedly applied in prototyped culture systems varying in the volume of vessels, i.e., from ca. $1.0 \mathrm{~cm}^{3}$ to $100 \mathrm{~cm}^{3}$. Some examples of two-liquid culture systems that integrated immiscible aqueous phases of culture media and liquid PFC in the forms of dispersed droplets or continuous layers are briefly presented in Table 4 . More examples have been frequently discussed, for example, in a number of previously published reviews $[4,5,26]$.

Table 4. Examples of two-liquid culture systems integrating immiscible aqueous culture media and dispersed or layered liquid PFCs.

\begin{tabular}{|c|c|c|c|c|}
\hline $\begin{array}{l}\text { Type of Two } \\
\text { Liquids System }\end{array}$ & $\begin{array}{c}\text { Total } \\
\text { Volume }\end{array}$ & Vessel & Biomass & Reference \\
\hline \multirow{4}{*}{$\begin{array}{c}\text { Dispersion of } \\
\text { PFC in aqueous } \\
\text { phase }\end{array}$} & $100 \mathrm{~cm}^{3}$ & $\begin{array}{c}500 \mathrm{~cm}^{3} \text { TubeSpin } \\
\text { disposable bioreactor }\end{array}$ & $\begin{array}{c}\text { Crypthecodinium } \\
\text { cohnii }\end{array}$ & [27] \\
\hline & $5 \mathrm{~cm}^{3}$ & $\begin{array}{l}\mathrm{T}-75\left(150 \mathrm{~cm}^{3}\right) \text { flasks on } \\
\text { rocking platform }\end{array}$ & $\beta$ TC-tet cells & [28] \\
\hline & $2 \mathrm{~cm}^{3}$ & $\begin{array}{l}\text { 6-wells disposable plates, } \\
\text { static culture }\end{array}$ & RINm5F $\beta$-cells & [29] \\
\hline & $0.3 \mathrm{~cm}^{3}$ & $\begin{array}{l}1.0 \mathrm{~cm}^{3} \text { cylindrical well, } \\
\text { static culture }\end{array}$ & $\begin{array}{l}\text { 3T3-L1 and } \\
\text { SV-T2 cells }\end{array}$ & [30] \\
\hline \multirow{5}{*}{$\begin{array}{l}\text { Contacting } \\
\text { continuous } \\
\text { layers of PFC } \\
\text { and aqueous } \\
\text { phase }\end{array}$} & $100 \mathrm{~cm}^{3}$ & $\begin{array}{l}300 \mathrm{~cm}^{3} \text { Erlenmeyer } \\
\text { flasks on orbital shaker }\end{array}$ & $\begin{array}{c}\text { Nicotiana } \\
\text { tabacum BY-2 }\end{array}$ & [10] \\
\hline & $35 \mathrm{~cm}^{3}$ & $\begin{array}{l}250 \mathrm{~cm}^{3} \text { Erlenmeyer } \\
\text { flasks on orbital shaker }\end{array}$ & $\begin{array}{l}\text { hairy roots of } \\
\text { Taxus } \times \text { media }\end{array}$ & [31] \\
\hline & $3 \mathrm{~cm}^{3}$ & $\begin{array}{l}\text { 6-/24-wells disposable } \\
\text { plates, static culture }\end{array}$ & $\begin{array}{l}\text { human } \\
\text { mesenchymal } \\
\text { stem cells }\end{array}$ & [8] \\
\hline & $2 \mathrm{~cm}^{3}$ & $\begin{array}{l}\text { 24-wells disposable plates, } \\
\text { static culture }\end{array}$ & C2C12 cells & [32] \\
\hline & $1.5 \mathrm{~cm}^{3}$ & $\begin{array}{l}1.5 \mathrm{~cm}^{3} \text { centrifuging } \\
\text { tubes, static cultures }\end{array}$ & B16 cells & [9] \\
\hline
\end{tabular}

From the perspective of mass transfer characteristics, systems of two liquids containing aqueous phase and liquid PFC have not been thoroughly described, probably due to the 
lack of simply-applied practical methods of measuring respiratory gas levels, i.e., $\mathrm{O}_{2}$ and $\mathrm{CO}_{2}$, in the liquid phase of PFD. Additionally, the rarely available literature data focused on such issues may be interpreted as incoherent.

The physical absorption of oxygen in aqueous media has been studied by measuring the values of $k_{L} a$ as the overall liquid-side mass transfer coefficient. Therefore, the mass transfer rate without chemical reaction was investigated. Both $\mathrm{PBS}$ and $\mathrm{dH}_{2} \mathrm{O}$ are recommended media to investigate the physical absorption of oxygen, including in single-use bioreactors, and such systems are also suitable for practical approximation of culture conditions [33]. To widen the applicability of the results presented in the current study, all experiments were performed at $37{ }^{\circ} \mathrm{C}\left(t_{\mathrm{C}}\right)$, according to the physiological requirements of most certified lines of mammalian cells, which are commonly in vitro cultured in submerged forms in disposable bioreactor systems. Such an assumption allowed comparison of the results reported in the present study with the data obtained for a range of in vitro cultures of isolated mammalian cells performed in a WAVE 25 system equipped with a Cellbag.

In our opinion, to fully recognize the oxygen transfer phenomena that occurred in the rocked system of two immiscible liquids, i.e., aqueous phase and liquid perfluorochemical, we propose the introduction of two factors: $f$, dependent on $a$; and $E^{\mathrm{PFD}}$, dependent on $k_{\mathrm{L}} a$. These factors, i.e., $f$ and $E^{\mathrm{PFD}}$, are not typically applied in bioprocess engineering. However, analysis of their values obtained in the studied system facilitated the understanding of observed relationships between the level of the obtained $k_{\mathrm{L}} a$ coefficient and operational parameters, i.e., $\alpha$ and $\omega$, defining conditions of wave-assisted agitation.

In the case of the $f$ factor, the dimensional exponential correlation methodology was proposed to generalize the obtained values of $f$ that can possibly be obtained under waveassisted agitation conditions, and not only those restricted to the WAVE 25 bioreactor. Two similar forms of dimensional exponential correlations, which depend only on $\alpha$ and $\omega$, for both studied aqueous phases, i.e., $\mathrm{dH}_{2} \mathrm{O}$ (Equation (9)) and PBS (Equation (10)), were proposed with the following forms:

$$
\begin{gathered}
f_{\mathrm{dH}_{2} \mathrm{O}}=8.588 \times \omega^{0.259} \times(\sin \alpha)^{0.275} \\
f_{\mathrm{PBS}}=8.066 \times \omega^{0.344} \times(\sin \alpha)^{0.376}
\end{gathered}
$$

According to the multidimensional regression analysis, the values of all constants refining Equations (9) and (10) were found. The parity plots are shown in Figure 5 in order to verify the correctness of both correlations. As can be easily seen, the values of $f_{\mathrm{dH}_{2} \mathrm{O}}$ and $f_{\text {PBS }}$ factors were predicted with the relative error at similar values, i.e., $23-24 \%$, by the correlations (9) and (10).
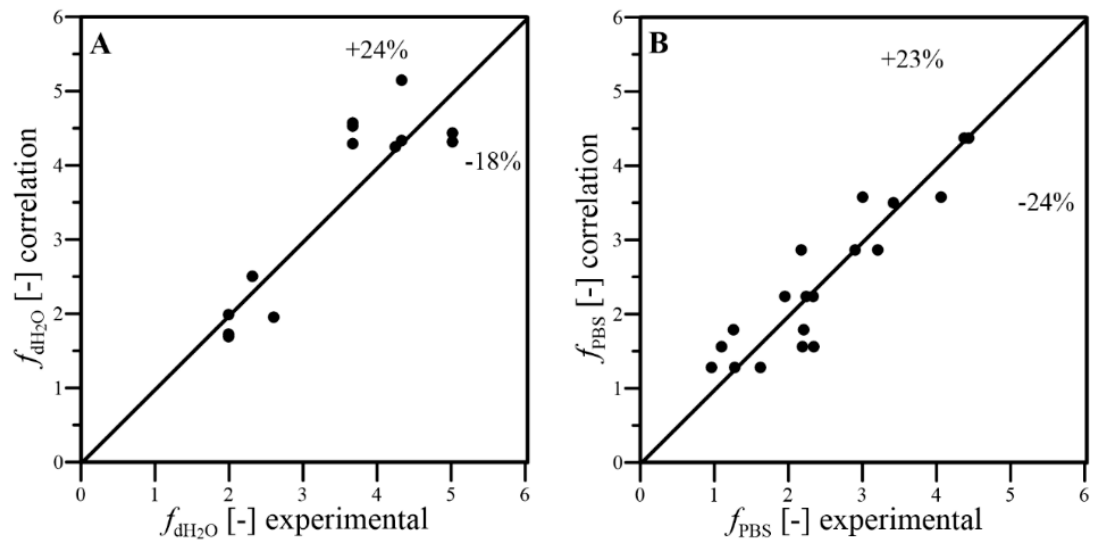

Figure 5. Parity plots of the $f$ values predicted by dimensional correlations for $\mathrm{dH}_{2} \mathrm{O}(\mathbf{A})$ and PBS (B), i.e., based on Equations (9) and (10), respectively. 
Similarly, in the case of the $E^{\mathrm{PFD}}$ factor, the dimensional exponential correlation methodology was proposed for the generalized estimation of the values of $E^{\mathrm{PFD}}$ that can possibly be obtained under various conditions of wave-assisted agitation for a broader range of operating parameter values than those presented in Table 3. Two similar forms of dimensional exponential correlations, which analogously depend on three operational parameters that significantly influence the $k_{\mathrm{L}} a$ level under wave-assisted agitation, i.e., $\alpha$, $\omega$, and $Q_{G}$, for both studied aqueous phases independently supplemented with PFD, i.e., for $E_{\mathrm{dH}}^{\mathrm{PFD}}$ (Equation (11)) and $E_{\mathrm{PBS}}^{\mathrm{PFD}}$ (Equation (12)), were proposed in the following forms:

$$
\begin{aligned}
& E_{\mathrm{dH} 2}^{\mathrm{PFD}}=0.185 \times \omega^{0.669} \times(\sin \alpha)^{0.183} \times Q_{\mathrm{G}}^{-0.169} \\
& E_{\mathrm{PBS}}^{\mathrm{PFD}}=0.195 \times \omega^{0.669} \times(\sin \alpha)^{0.183} \times Q_{\mathrm{G}}^{-0.169}
\end{aligned}
$$

with the values of all constants found according to the multidimensional regression analysis.

The parity plots are shown in Figure 6 to verify the correctness of both introduced dimensional correlations. As can be easily seen, the values of $E_{\mathrm{dH}_{2} \mathrm{O}}^{\mathrm{PFD}}$ and $E_{\mathrm{PBS}}^{\mathrm{PFD}}$ factors were predicted by the correlations (11) and (12) with the relative errors of $15-17 \%$ and $23-26 \%$, respectively.
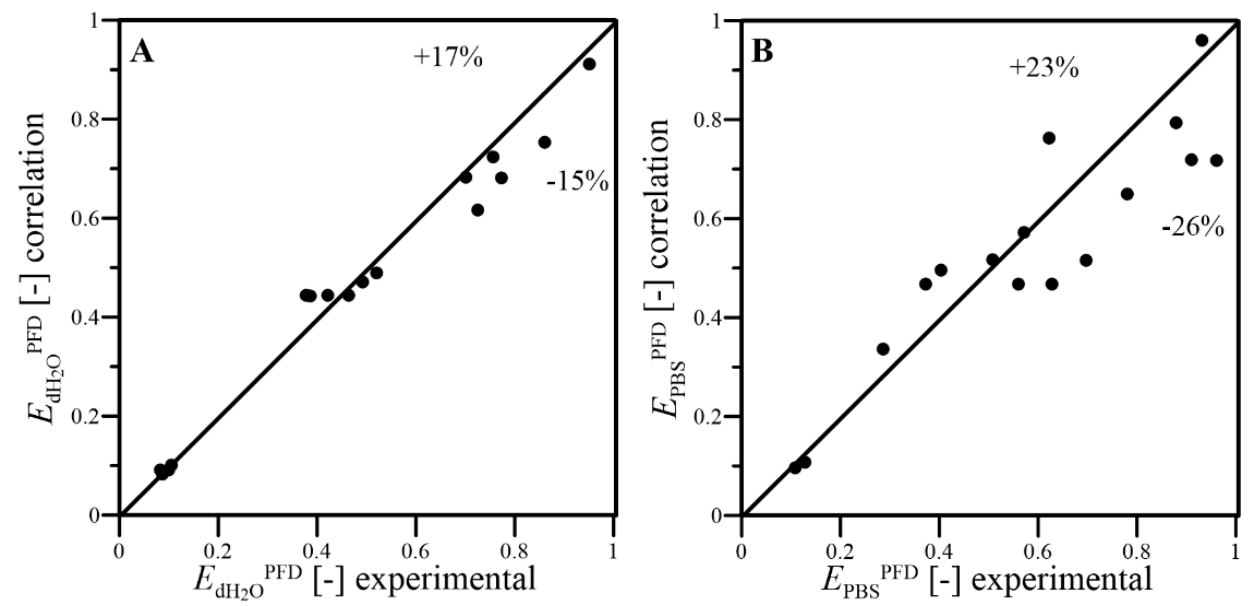

Figure 6. Parity plots of the $E$ factor values predicted by dimensional correlations: $E_{\mathrm{dH}_{2} \mathrm{O}}^{\mathrm{PFD}}(\mathbf{A})$ and $E_{\mathrm{PBS}}^{\mathrm{PFD}}(\mathbf{B})$, i.e., based on Equations (11) and (12), respectively.

Moreover, in the case of the $E_{\mathrm{dH}_{2} \mathrm{O}}^{\mathrm{PFD}}$ and $E_{\mathrm{PBS}}^{\mathrm{PFD}}$ factors, it is worth noting that all levels of both factor values that were calculated and presented in Table 3 were less than 1 . These indicate that the addition of PFD reduced the values of the $k_{\mathrm{L}} a$ coefficient in comparison to values reached for aqueous phases (i.e., $\mathrm{dH}_{2} \mathrm{O}$ or PBS) without PFD supplementation. Supposedly, supplementation of the studied systems with PFD hypothetically induced the changes in hydrodynamics inside the disposable bag-like container. The worsening of mass transfer in the two liquid systems was observed. This may be caused by the limitation of circulation in liquid phases at the interface of contacting immiscible $\mathrm{dH}_{2} \mathrm{O}$ (or PBS) and PFD due to decreases in the local liquid velocity. Such a phenomenon might indicate that the investigated liquid phase was not mixed properly and that the oxygen transfer rate was limited in the total volume of the liquid phase. The waving two-liquid system containing aqueous phase (as the upper liquid phase) and PFD (as the lower liquid phase) is characterized by different hydrodynamics than the waving individual aqueous phase, i.e., $\mathrm{dH}_{2} \mathrm{O}$ or PBS, without PFD. We hypothesize that in the case of PFD presence in the studied systems, the circulation of the aqueous phase was significantly less intensive. Similarly, the surface of the aqueous phase was renewed less intensively. These two effects may be interpreted as phenomena that have a strong negative influence on the $k_{\mathrm{L}} a$ values reached for the waving two liquid phase $\mathrm{dH}_{2} \mathrm{O}-\mathrm{PFD}$ and PBS-PFD systems compared to 
waving $\mathrm{dH}_{2} \mathrm{O}$ or PBS without PFD. Therefore, a decrease in the value of the $k_{L} a$ coefficient will not disturb oxygenation if oxygen is still available in a liquid PFD-based reservoir. Thus, all of this might hypothetically explain the values lower than 1, estimated for both $E_{\mathrm{dH}_{2} \mathrm{O}}^{\mathrm{PFD}}$ and $E_{\mathrm{PBS}}^{\mathrm{PFD}}$.

The correlations for $E_{\mathrm{dH} 2 \mathrm{O}}{ }^{\mathrm{PFD}}$ and $E_{\mathrm{PBS}}{ }^{\mathrm{PFD}}$ introduced by Equations (11) and (12), respectively, are very similar in their forms. Only the value of the absolute term varied in proposed correlations, which may result from different values of the oxygen diffusion coefficient estimated for $\mathrm{dH}_{2} \mathrm{O}$ and PBS, i.e., $3.06 \times 10^{-9} \mathrm{~m}^{2} \mathrm{~s}^{-1}$ vs. $2.50 \times 10^{-9} \mathrm{~m}^{2}$ $\mathrm{s}^{-1}$, respectively [34]. The exact values of the other constants refining both discussed dimensional correlations (i.e., Equations (11) and (12)) allowed us to hypothesize that the hydrodynamics of wave-type mixing concerning both studied systems of two liquidsaqueous phase (i.e., $\mathrm{dH}_{2} \mathrm{O}$ or PBS) and PFD-were identical.

In our opinion, characterization of mass transfer effects based on such atypical factors as $E^{\mathrm{PFD}}$ may be challenging or problematic to interpret and further discuss, due to the lack of available data in the literature concerning processes of aeration/oxygenation or mixing of two-liquid systems integrating immiscible aqueous phase and PFD. Correlations for predicting the $k_{\mathrm{L}} a$ values are significantly more appreciated and applicable due to commonly known quantitative characteristics of aeration conditions described by the $k_{\mathrm{L}} a$ coefficient. Thus, in the case of the considered aqueous phases not supported with PFD, the dimensional exponential correlation methodology may also be applied for estimation of the values of the $k_{\mathrm{L}} a$ coefficient that can be possibly obtained under various conditions of wave-assisted agitation defined by $\alpha$ and $\omega$, and gas-phase flow characterized by $Q_{\mathrm{G}}$, as follows:

$$
\begin{aligned}
k_{\mathrm{L}} a_{\mathrm{dH} \mathrm{H}_{2} \mathrm{O}} & =10.379 \times \omega^{0.594} \times(\sin \alpha)^{0.443} \times Q_{\mathrm{G}}^{0.592} \\
k_{\mathrm{L}} a_{\mathrm{PBS}} & =7.503 \times \omega^{0.594} \times(\sin \alpha)^{0.443} \times Q_{\mathrm{G}}^{0.592}
\end{aligned}
$$

Therefore, to verify the correctness of dimensional correlations for predicting the values of the $k_{\mathrm{L}} a_{\mathrm{dH}} \mathrm{O}$ and $k_{\mathrm{L}} a_{\mathrm{PBS}}$ coefficients, the parity plots are presented in Figure 7. Values of $k_{\mathrm{L}} a_{\mathrm{dH}_{2} \mathrm{O}}$ and $k_{\mathrm{L}} a_{\mathrm{PBS}}$ were predicted by the correlations (13) and (14) with similar relative error values not higher than $31 \%$ and $28 \%$, respectively.
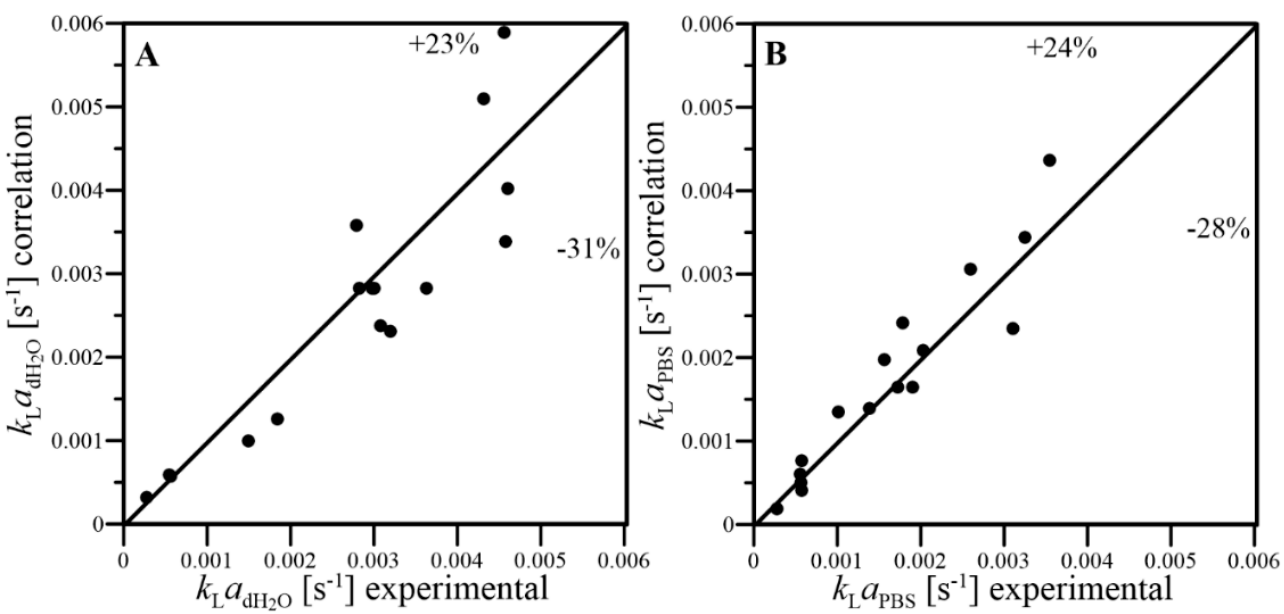

Figure 7. Parity plots of the values of $k_{\mathrm{L}} a_{\mathrm{dH}_{2} \mathrm{O}}(\mathbf{A})$ and $k_{\mathrm{L}} a_{\mathrm{PBS}}(\mathbf{B})$, predicted by dimensional correlations (13) and (14), respectively.

Finally, based on the above-presented correlations on the $k_{\mathrm{L}} a$ coefficients and the $E$ factors, i.e., Equations (11)-(14), respectively, dimension exponential correlation for prediction of values of the $k_{\mathrm{L}} a$ coefficient that can possibly be obtained in two-liquid systems containing aqueous phase and PFD (i.e., $\mathrm{dH}_{2} \mathrm{O}-\mathrm{PFD}$ and PBS-PFD) waving according to the operational parameters in WAVE 25, were proposed in the following forms:

$$
k_{\mathrm{L}} a_{\mathrm{dH} \mathrm{H}_{2} \mathrm{O}-\mathrm{PFD}}=k_{\mathrm{L}} a_{\mathrm{dH}_{2} \mathrm{O}} \times E_{\mathrm{dH}_{2} \mathrm{O}}^{\mathrm{PFD}}=1.920 \times \omega^{1.263} \times(\sin \alpha)^{0.626} \times Q_{\mathrm{G}}^{0.422}
$$




$$
\begin{aligned}
k_{\mathrm{L}} a_{\mathrm{PBS}-\mathrm{PFD}}= & k_{\mathrm{L}} a_{\mathrm{PBS}} \times E_{\mathrm{PBS}}^{\mathrm{PFD}}=1.853 \times \omega^{1.263} \times(\sin \alpha)^{0.626} \times Q_{\mathrm{G}}{ }^{0.422} k_{\mathrm{L}} a_{\mathrm{PBS}-\mathrm{PFD}} \\
& =k_{\mathrm{L}} a_{\mathrm{PBS}} \times E_{\mathrm{PBS}}^{\mathrm{PFD}}=1.920 \times \omega^{1.263} \times(\sin \alpha)^{0.626} \times Q_{\mathrm{G}}^{0.422}
\end{aligned}
$$

The parity plots are shown in Figure 8 . The values of $k_{\mathrm{L}} a_{\mathrm{dH}} \mathrm{O}-\mathrm{PFD}$ and $k_{\mathrm{L}} a_{\mathrm{PBS}-\mathrm{PFD}}$ were predicted with the relative errors of $23-31 \%$ and $27-34 \%$, respectively.

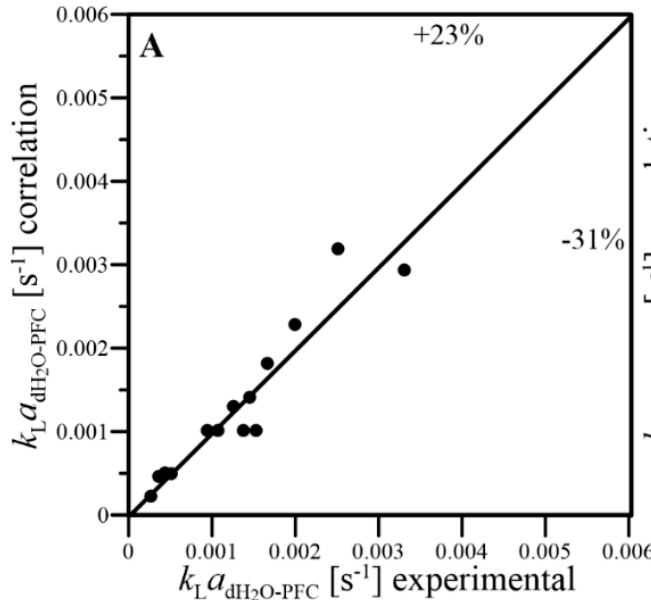

Figure 8. Parity plots of the values of $k_{\mathrm{L}} a_{\mathrm{dH}} \mathrm{O}-\mathrm{PFD}(\mathbf{A})$ and $k_{\mathrm{L}} a_{\mathrm{PBS}-\mathrm{PFD}}(\mathbf{B})$, predicted by dimensional correlations (15) and (16), respectively.

The dimensional correlations (15) and (16) summarize the quantitative characterization of oxygen transfer effects in two-liquid systems of aqueous phase (i.e., $\mathrm{dH}_{2} \mathrm{O}$ or PBSbuffer) containing PFD applied as the gas carrier, and mixed under conditions of waveassisted agitation performed in a bag-like disposable container (e.g., Cellbag) of a single-use bioreactor.

\section{Conclusions}

Oxygen transfer effects in an aqueous and liquid perfluorochemical system subjected to wave-assisted agitation in a disposable bag-like container fixed in a single-use bioreactor were recognized and discussed in detail. Two originally introduced factors- $f$, dependent on $a$; and $E^{\mathrm{PFD}}$, dependent on $k_{\mathrm{L}} a$-facilitated the quantitative identification of the mass transfer effects in the system of two contacted immiscible liquids: $\mathrm{dH}_{2} \mathrm{O}$ or PBS and PFD, continuously subjected to oscillatory-driven wave-assisted agitation in a Cellbag fixed in a WAVE 25 bioreactor. The results presented in the study can be concluded as follows:

- Lower levels of the $k_{\mathrm{L}} a$ coefficient noted for PBS-containing systems, i.e., PBS and PBS-PFD than for systems with $\mathrm{dH}_{2} \mathrm{O}$, i.e., $\mathrm{dH}_{2} \mathrm{O}$ and $\mathrm{dH}_{2} \mathrm{O}-\mathrm{PFD}$, resulted from the lower value of oxygen diffusion coefficient for $\mathrm{dH}_{2} \mathrm{O}$ if compared to PBS (i.e., $3.06 \times$ $10^{-9} \mathrm{~m}^{2} \mathrm{~s}^{-1}$ vs. $2.50 \times 10^{-9} \mathrm{~m}^{2} \mathrm{~s}^{-1}$, respectively);

- The values of $\alpha$ and $\omega$ had monotonically increased influence on the value of the $f$ factor;

- The values of both $E_{\mathrm{dH}_{2} \mathrm{O}}^{\mathrm{PFD}}$ and $E_{\mathrm{PBS}}^{\mathrm{PFD}}$ factors increased monotonically according to the increase in $\alpha$ and $\omega$, but the increase in the value of $Q_{G}$ resulted in a monotonical decrease in values of both $E_{\mathrm{dH}_{2} \mathrm{O}}^{\mathrm{PFD}}$ and $E_{\mathrm{PBS}}^{\mathrm{PFD}}$;

- Supplementation of $\mathrm{dH}_{2} \mathrm{O}$ with PFD caused the significant decrease in values of the $k_{\mathrm{L}} a$ coefficient reached in the system of $\mathrm{dH}_{2} \mathrm{O}-\mathrm{PFD}$ in comparison to the $k_{\mathrm{L}} a$ values reached for pure $\mathrm{dH}_{2} \mathrm{O}$, which resulted in values of $E_{\mathrm{dH}_{2} \mathrm{O}}^{\mathrm{PFD}}$ and $E_{\mathrm{PBS}}^{\mathrm{PFD}}$ of less than 1.0 for the majority of the studied variants;

- $\quad$ The waving two-liquid system containing aqueous phase (as the upper liquid phase) and PFD (as the lower liquid phase) is characterized by different hydrodynamics than that of the waving individual aqueous phase, i.e., $\mathrm{dH}_{2} \mathrm{O}$ or PBS, without PFD; 
- The dimensional correlations proposed for prediction of $k_{\mathrm{L}} a$ coefficient, in addition to $f$ and $E^{\text {PFD }}$ factors, well fitted the experimental results with satisfactory levels of the relative errors; thus, they can be applied to predict the conditions of oxygen transfer effects reached under continuous wave-assisted agitation of systems containing aqueous phase and liquid PFC;

- Lower $k_{\mathrm{L}} a$ values noted for PFD-supplemented systems may indicate hypoxia conditions affecting biomass maintained in the cell culture systems containing liquid PFC.

Author Contributions: Conceptualization, K.W., P.S. and M.P.; methodology, K.W., P.S. and M.P.; software, K.W.; validation, K.W.; formal analysis, K.W. and P.S.; investigation, K.W.; resources, M.P.; writing-original draft preparation, K.W. and P.S.; writing—review and editing, M.P.; visualization, K.W.; supervision, M.P.; project administration, M.P.; funding acquisition, M.P. All authors have read and agreed to the published version of the manuscript.

Funding: This work was supported by the budget sources for the National Centre for Science, Poland, under OPUS-9 grant no. 2015/17/B/ST8/00631.

Institutional Review Board Statement: Not applicable.

Informed Consent Statement: Not applicable.

Data Availability Statement: The data presented in this study are available on request from the corresponding author.

Conflicts of Interest: The authors declare no conflict of interest.

\section{List of Symbols}

$a$

$a_{\mathrm{dH}_{2} \mathrm{O}}$

$a_{\mathrm{PBS}}$

$a^{\prime}$

$c_{\mathrm{L}}$

$c_{\mathrm{L}}^{*}$

$D_{\mathrm{L}}$

$E^{\mathrm{PFD}}$

$E_{\mathrm{PFD}}^{\mathrm{P}}$

${ }_{\mathrm{dH}}^{\mathrm{PFD}}$

$F$

$f$

$f_{\mathrm{dH}_{2} \mathrm{O}}$

$f_{\mathrm{PBS}}$

$V_{\mathrm{L}}$

$k_{\mathrm{L}}$

$\mathrm{k}_{\mathrm{L}} \mathrm{a}$

$k_{\mathrm{L}} a_{\mathrm{dH}_{2} \mathrm{O}}$

$k_{\mathrm{L}} a_{\mathrm{dH}} \mathrm{O}-\mathrm{PFD}$

$k_{\mathrm{L}} a_{\mathrm{PBS}}$

$k_{\mathrm{L}} a_{\mathrm{PBS}-\mathrm{PFD}}$

$p_{\mathrm{N} 2}$

$p_{\mathrm{O} 2}$

$t$

$t_{\mathrm{C}}$

$Q_{\mathrm{G}}$ interfacial area of mass transfer $\left(\mathrm{m}^{-1}\right)$

interfacial area of mass transfer for distilled water $\left(\mathrm{m}^{-1}\right)$

interfacial area of mass transfer for phosphate-buffered saline $\left(\mathrm{m}^{-1}\right)$

physical interfacial area estimated for non-mixed conditions $\left(\mathrm{m}^{-1}\right)$

molar concentration of oxygen dissolved in the liquid phase $\left(\mathrm{mol} \mathrm{m}^{-3}\right)$

equilibrium concentration of oxygen dissolved in the liquid phase $\left(\mathrm{mol} \mathrm{m}^{-3}\right)$

coefficient of oxygen diffusivity in the liquid phase $\left(\mathrm{m}^{2} \mathrm{~s}^{-1}\right)$

enhancement factor (-)

enhancement factor for distilled water and perfluorodecalin (-)

enhancement factor for phosphate-buffered saline and perfluorodecalin (-)

interfacial area between gas and liquid phases $\left(\mathrm{m}^{2}\right)$

interface development factor (-)

interface development factor for distilled water (-)

interface development factor for phosphate-buffered saline (-)

volume of the liquid phase $\left(\mathrm{m}^{3}\right)$

liquid-side mass transfer coefficient $\left(\mathrm{s}^{-1}\right)$

volumetric liquid-side mass transfer coefficient $\left(\mathrm{s}^{-1}\right)$

volumetric liquid-side mass transfer coefficient for distilled water $\left(\mathrm{s}^{-1}\right)$

volumetric liquid-side mass transfer coefficient for distilled water

and perfluorodecalin $\left(\mathrm{s}^{-1}\right)$

volumetric liquid-side mass transfer coefficient for phosphate-buffered saline $\left(\mathrm{s}^{-1}\right)$

volumetric liquid-side mass transfer coefficient for phosphate-buffered saline

and perfluorodecalin $\left(\mathrm{s}^{-1}\right)$

nitrogen partial pressure in the gas phase $(\mathrm{Pa})$

oxygen partial pressure in the gas phase $(\mathrm{Pa})$

time (s)

temperature $\left({ }^{\circ} \mathrm{C}\right)$

volumetric gas flow thought bag-like container $\left(\mathrm{m}^{3} \mathrm{~s}^{-1}\right)$ 


\section{Greek Symbols}

$\begin{array}{ll}\alpha & \text { angle of oscillations }\left({ }^{\circ}\right) \\ \tau & \text { contact time (s) } \\ \omega & \text { frequency of oscillations }\left(\mathrm{s}^{-1}\right)\end{array}$

$\begin{array}{ll}\text { Abbreviations } \\ \text { BBD } & \text { Box-Behnken design } \\ \beta \text { TC-tet } & \text { mouse pancreatic islet } \beta \text {-cell line } \\ \text { B16 } & \text { mouse skin melanoma cell line } \\ \mathrm{CBCU} & \text { central bioreactor control unit } \\ \mathrm{C} 2 \mathrm{C} 12 & \text { mouse myoblast cell line } \\ \mathrm{dH}_{2} \mathrm{O} & \text { sterilized distilled water } \\ \mathrm{DO} & \text { dissolved oxygen } \\ \mathrm{DoE} & \text { Design of Experiment } \\ \mathrm{N}_{2} & \text { nitrogen } \\ \mathrm{O}_{2} & \text { oxygen } \\ \mathrm{PBS} & \text { phosphate-buffered saline } \\ \mathrm{PFC} & \text { perfluorochemical } \\ \mathrm{PFD} & \text { perfluorodecalin } \\ \mathrm{RINm} 5 \mathrm{~F} & \text { rat pancreatic islet } \beta \text {-cell line } \\ \text { SV-T2 } & \text { mouse embryonic fibroblast cell line } \\ \text { WAVE 25 } & \text { ReadyToProcess WAVE }{ }^{\mathrm{TM}} 25 \text { bioreactor } \\ \text { 3T3-L1 } & \text { primary mouse embryonic fibroblast cell line }\end{array}$

\section{References}

1. Cabrales, P.; Intaglietta, M. Blood substitutes: Evolution from non-carrying to oxygen and gas carrying fluids. ASAIO J. 2013, 59, 337-354. [CrossRef]

2. Sarkar, S.; Paswan, A.; Prakas, S. Liquid ventilation. Anesth. Essays Res. 2014, 8, 277-282. [CrossRef]

3. Krafft, M.P.; Riess, J.G. Perfluorocarbons: Life sciences and biomedical uses. J. Polym. Sci. 2007, 45, 1185-1198. [CrossRef]

4. Ntwampe, S.K.O.; Williams, C.C.; Sheldon, M.S. Water-immiscible dissolved oxygen carriers in combination with Pluronic F 68 in bioreactors. Afr. J. Biotechnol. 2010, 9, 1106-1114. [CrossRef]

5. Pilarek, M. Liquid perfluorochemicals as flexible and efficient gas carriers applied in bioprocess engineering: An updated overview and future prospects. Chem. Process Eng. 2014, 35, 463-487. [CrossRef]

6. Riess, J.G. Perfluorocarbon-based oxygen delivery. Artif. Cell Blood Sub. Biotechnol. 2006, 34, 567-580. [CrossRef] [PubMed]

7. Sobieszuk, P.; Pilarek, M. Absorption of $\mathrm{CO}_{2}$ into perfluorinated gas carrier in the Taylor gas-liquid flow in a microchannel system. Chem. Process Eng. 2012, 33, 595-602. [CrossRef]

8. Hanga, M.P.; Murasiewicz, M.; Pacek, A.W.; Nienow, A.W.; Coopman, K.; Hewitt, C.J. Expansion of bone marrow-derived human mesenchymal stem/stromal cells (hMSCs) using a two-phase liquid/liquid system. J. Chem. Technol. Biotechnol. 2017, 96, 1577-1589. [CrossRef] [PubMed]

9. Miyajima, H.; Kasuya, M.C.; Hatanaka, K. Dodecafluoroheptanol: Oxygen reservoir for the culture of mouse melanoma B16 cells. J. Fluor. Chem. 2014, 163, 46-49. [CrossRef]

10. Pilarek, M.; Dabkowska, K. Modelling of a hybrid culture system with a stationary layer of liquid perfluorochemical applied as oxygen carrier. Chem. Process Eng. 2016, 37, 149-158. [CrossRef]

11. Bąk, A.; Pilarek, M.; Podgórska, W.; Markowska-Radomska, A.; Hubacz, R. Surface properties of perfluorodecalin-containing liquid/liquid systems: The influence of Pluronic F-68 dissolved in the aqueous phase. J. Fluor. Chem. 2018, 215, 36-43. [CrossRef]

12. Fraker, C.A.; Mendez, A.J.; Inverardi, L.; Ricordia, C.; Stabler, C.L. Optimization of perfluoro nano-scale emulsions: The importance of particle size for enhanced oxygen transfer in biomedical applications. Colloids Surf. B 2012, 98, 26-35. [CrossRef]

13. Murasiewicz, H.; Nienow, A.W.; Hanga, M.P.; Coopman, K.; Hewitt, C.J.; Pacek, A.W. Engineering considerations on the use of liquid/liquid two-phase systems as a cell culture platform. J. Chem. Technol. Biotechnol. 2017, 92, 1690-1698. [CrossRef]

14. Lopes, A.G. Single-use in the biopharmaceutical industry: A review of current technology impact, challenges and limitations. Food Bioprod. Process. 2015, 93, 98-114. [CrossRef]

15. Singh, V. Method for Culturing Cells Using Wave-Induced Agitation. U.S. Patent 6190913, 20 February 2001.

16. Kazemzadeh, A.; Elias, C.; Tamer, M.; Lohi, A.; Ein-Mozaffari, F. Mass transfer in a single-use angled-shaft aerated stirred bioreactor applicable for animal cell culture. Chem. Eng. Sci. 2020, 219, 115606. [CrossRef]

17. Müller, M.; Husemann, U.; Greller, G.; Meusel, W.; Kraume, M. Heat transfer characteristics of a stirred single-use bioreactor. Biochem. Eng. J. 2018, 140, 168-177. [CrossRef]

18. Junne, S.; Neubauer, P. How scalable and suitable are single-use bioreactors? Curr. Opin. Biotechnol. 2018, 53, 240-247. [CrossRef] [PubMed] 
19. Wierzchowski, K.; Grabowska, I.; Pilarek, M. Efficient propagation of suspended HL-60 cells in a disposable bioreactor supporting wave-induced agitation at various Reynolds number. Bioprocess Biosyst. Eng. 2020, 43, 1973-1985. [CrossRef] [PubMed]

20. Löffelholz, C.; Kaiser, S.C.; Kraume, M.; Eibl, R.; Eibl, D. Dynamic single-use bioreactors used in modern liter- and $\mathrm{m}^{3}$-scale biotechnological processes: Engineering characteristics and scaling up. Adv. Biochem. Eng. Biotechnol. 2014, 138, 1-44. [CrossRef]

21. Wierzchowski, K.; Kuźmińska, A.; Pilarek, M. Intensification of chondrocytes proliferation by microcarriers and wave-induced mixing: Reynolds number influence on CP5 cells growth. Chem. Eng. Process. 2021, 166, 108472. [CrossRef]

22. Pilarek, M.; Sobieszuk, P.; Wierzchowski, K.; Dąbkowska, K. Impact of operating parameters on values of a volumetric mass transfer coefficient in a single-use bioreactor with wave-induced agitation. Chem. Eng. Res. Des. 2018, 136, 1-10. [CrossRef]

23. Higbie, R. The rate of absorption of a pure gas into a still liquid during short periods of exposure. Trans. Am. Inst. Chem. Eng. 1935, 31, 365-389.

24. DeCoursey, W.J. Enhancement factors for gas absorption with reversible reaction. Chem. Eng. Sci. 1982, 37, 1483-1489. [CrossRef]

25. Ju, L.K. Enhancing oxygen transfer in bioreactors by perfluorocarbon emulsions. Biotechnol. Prog. 1991, 7, 323-329. [CrossRef]

26. Kumar, A.; Narta, U.K.; Azmi, W. The emergence of oxygen vectors in overcoming the challenges of oxygen transfer rate in aerobic bioprocesses. Curr. Eng. J. 2017, 4, 164-171. [CrossRef]

27. Hillig, F.; Annemüller, S.; Chmielewska, M.; Pilarek, M.; Junne, S.; Neubauer, P. Bioprocess development in single-use systems for heterotrophic marine microalgae. Chem. Ing. Tech. 2013, 85, 153-161. [CrossRef]

28. Goh, F.; Gross, J.D.; Simpson, N.E.; Sambanis, A. Limited beneficial effects of perfluorocarbon emulsions on encapsulated cells in culture: Experimental and modeling studies. J. Biotechnol. 2010, 150, 232-239. [CrossRef]

29. Maillard, E.; Juszczak, M.T.; Langlois, A.; Kleiss, C.; Sencier, M.C.; Bietiger, W.; Sanchez-Dominguez, M.; Krafft, M.P.; Johnson, P.R.V.; Pinget, M.; et al. Perfluorocarbon emulsions prevent hypoxia of pancreatic $\beta$-cells. Cell Transplant. 2012, 21, 657-669. [CrossRef]

30. Giaever, I.; Keese, C.R. Behavior of cells at fluid interfaces. Proc. Natl. Acad. Sci. USA 1983, 80, 219-222. [CrossRef]

31. Sykłowska-Baranek, K.; Rymaszewski, W.; Gaweł, M.; Rokicki, P.; Pilarek, M.; Grech-Baran, M.; Hennig, J.; Pietrosiuk, A. Comparison of elicitor-based effects on metabolic responses of Taxus $\times$ media hairy roots in perfluorodecalin-supported twophase culture system. Plant Cell Rep. 2019, 38, 85-99. [CrossRef]

32. Minami, K.; Mori, T.; Nakanishi, W.; Shigi, N.; Nakanishi, J.; Hill, J.P.; Komiyama, M.; Ariga, K. Suppression of myogenic differentiation of mammalian cells caused by fluidity of a liquid-liquid interface. ACS Appl. Mater. Interfaces 2017, 9, 30553-30560. [CrossRef] [PubMed]

33. Meusel, W.; Loffelholz, C.; Husemann, U.; Dreher, T.; Greller, G.; Kauling, J.; Eibl, D.; Kleebank, S.; Bauer, I.; Glockler, R.; et al. Recommendations for Process Engineering Characterisation of Single-Use Bioreactors and Mixing Systems by Using Experimental Methods, 2nd ed.; Dechema Biotechnologie: Frankfurt am Main, Germany, 2020.

34. Stroe-Biezen, S.A.M.; Janssen, A.P.M.; Janssen, L.J.J. Solubility of oxygen in glucose solutions. Anal. Chim. Acta 1993, 280, $217-222$. [CrossRef] 